assistance of Miss C. Harris and Mrs. H. Coats is gratefully acknowledged.

\section{REFERENCES}

Glick, S. M., Roth, J., Yalow, R. S., and Berson, S. A. (1963). Nature (Lond.), 199, 784.

Greenwood, F. C., Hunter, W. M., and Klopper, A. (1964). Brit. med. f., 1,22
Hunter, W. M., and Greenwood, F. C. (1962). Biochem. 7., 85, 39P. Lan (1964). Ibid., 91, 43.

Landon, J., Wynn, V., and James, V. H. T. (1963). 7. Endocr., 27, 183. Raben, M. S. (1959). Recent Progr. Hormone Res., 15, 71.

- and Hollenberg, C. H. (1959). 7. clin. Invest., 38, 484

Roth, J., Glick, S. M., Yalow, R. S., and Berson, S. A. (1963a). Science, 140, 987.

(1963b). Metabolism, 12, 577.

Unger, R. H., Eisentraut, A. M., and Madison, L. L. (1963). F. clin. Invest., 42, 1031.

Utiger, R. D., Parker, M. L., and Daughaday, W. H. (1962). Ibid., 41, 254.

\title{
Mannitol Therapy in Oliguria of Acute Onset
}

\author{
H. E. ELIAHOU,* B.A., M.D.
}

Brit. med. F., 1964, 1, 807-809

The protective action of mannitol on the ischaemic kidney was noted by Selkurt (1945) and reaffirmed experimentally by Hatcher et al. (1958) and Hostnik et al. (1959). Recent reports (Powers et al., 1957 ; Barry et al., 1961a, 1961b ; Lempert et al., 1961 ; Nesbit et al., 1962 ; Barry and Malloy, 1962 ; Seitzman et al., 1963) claim that the process of acute renal failure can be prevented or even reversed by the use of intravenous mannitol, provided this treatment is instituted early. But in all the clinical cases presented there is some doubt about whether actual reversal of acute renal failure had taken place. Experimental support of reversal has, however, been obtained. Murphy et al. (1963) have shown a definite increase in the directly measured renal blood-flow during sustained haemorrhagic hypotension in dogs, without having increased the blood-volume. Leonhardt and Landes (1963) found that infusion of mannitol in six dehydrated patients increased the partial pressure of oxygen in the urine from a mean of $29 \mathrm{~mm}$. to a mean of $67 \mathrm{~mm}$. $\mathrm{Hg}$, an average rise of $124 \%$.

Our intention was to examine the possible beneficial effects of mannitol clinically, and to investigate whether reversal of acute renal failure does actually occur. If proper evaluation of mannitol therapy is to be attempted, its effect in oliguria of extrarenal origin and in oliguria of true renal origin should be considered separately. In this study this differentiation has been attempted, using the power of the kidneys to concentrate as the criterion. It has been shown by Gullick and Raisz (1960) that the concentrating ability, though markedly decreased during operation, returns toward pre-operative values the next day. It therefore follows that any serious decrease in the concentrating ability of the kidneys in the presence of oliguria, later than 24 hours post-operatively, would seem to indicate incipient acute parenchymatous renal failure, provided the kidneys were normal prior to the operation.

\section{Methods}

This study is based upon the finding that in oliguria of extrarenal origin, when the kidneys are still normal, the urinary urea concentration and the urine osmolality are high; the urine-urea concentration being well over $1,500 \mathrm{mg} . / 100$ ml. (Shackman et al., 1960 ; Molloy, 1962 ; Eliahou, 1963) and the urine osmolality being at least two and a half times that of the plasma (Jacobson et al., 1962), whereas in acute renal failure the kidneys fail to concentrate and the urinary urea and osmolality tend to approach that of the blood.

* From the Nephrology Unit, Tel-Hashomer Government Hospital, TelHashomer, Israel.
Only patients whose kidneys. functioned well prior to the onset of oliguria were considered. This was determined in the general-hospital wards by the absence of a history of serious renal disease, by a normal specific gravity, by the presence of a normal creatinine clearance, and by a normal blood-urea level. In the few emergency cases an adequate history of no renal disease, together with a previous negative routine check-up of the urine, sufficed. To avoid the transient decrease in the concentrating ability during operations (Gullick and Raisz, 1960), the urines of all the surgical patients included in this study were first examined, and mannitol was administered, at least 24 hours after the end of the operation.

Samples of fresh urine were taken from the patients soon after oliguria was established and were examined for osmolality and urea concentration. Osmolality was always promptly determined. If the samples were taken at night the urea was determined the next day, after having covered the urine with toluol and stored it in a refrigerator. Fresh samples of urine were examined the next morning after the administration of mannitol. This was usually within 10 to 18 hours after its infusion.

Urine-urea concentration was determined by the Technicon autoanalyzer. Urine osmolality was determined by the Fiske osmometer.

In all the patients, excepting Case 1 (see Table and case report), $250 \mathrm{ml}$. of $10 \%$ mannitol was rapidly infused intravenously at the rate of 80 to 100 drops a minute. This was followed by intravenous fluids according to the requirements of the individual patient, depending upon the fluid balancesheet.

\section{Results}

\section{Oliguric Patients with Low Urine Concentration}

Ten severely ill patients are included in this group. Except for the case of severe heat-stroke, they were all surgical cases (see Table). These patients at the time of examination, after the onset of oliguria, had a low urinary urea concentration as well as a low urine osmolality, in spite of a rise in blood urea. The values were not low enough to justify the diagnosis of acute renal failure. However, they were not high enough to be compatible with the diagnosis of normal kidneys. Since acute renal failure takes some time to develop, it is possible to interpret these findings as being compatible with partial or "incipient" renal failure. According to the clinical events and the laboratory data, therefore, the cases described could 
be interpreted as having been well on their way towards developing " total acute renal failure."

In all the cases the urine output rose significantly. Except for Cases 7 and 8, both the urine-urea concentration and the urine osmolality were significantly higher after the infusion of mannitol. In Cases 7 and 8 there was a moderate decrease in urine concentration associated with marked diuresis and an increase in the total urinary urea output. In Case 8, for example, the urea output rose from 1.26 g. to $19.33 \mathrm{~g} . / 24$ hours.

The blood-urea level, though included in the table, cannot be considered in evaluating the effect of the mannitol, since it is dependent upon many other factors, especially the catabolic rate. In most of the cases, however, it decreased to normal within two to four days.

In this group, therefore, it is possible to assume that renal failure, which was partial or incipient, was reversed by the use of intravenous mannitol. The following case report illustrates this assumption clearly.

\section{Case 1}

A 19-year-old youth suffered from a gunshot wound in the back. The bullet had shattered a rib, tore the liver and the upper pole of the right kidney, and involved the vertebrae. He had partial paralysis of both lower limbs. On lumbar puncture the cerebospinal fluid was grossly bloody. At laparotomy free blood was seen in the peritoneal cavity. The liver had a large defect on its superior surface, with a tear extending all the way down to its inferior surface. A large retroperitoneal haematoma was evacuated. The torn upper pole of the right kidney was repaired. Scattered pieces of adrenal tissue were seen in the area. The intestines were not involved. The ninth rib was shattered and pieces of it were seen in the area of the inlet wound. During the day of the operation and the next day the blood-pressure was unstable. The systolic pressure fluctuated between 90 and $120 \mathrm{~mm}$. Hg. Noradrenaline infusion was needed only for short periods.

During the first eight hours after the operation he passed $100 \mathrm{ml}$. of urine, with an osmolality of $600 \mathrm{mOsm} / \mathrm{kg}$. During eight hours on the next day only a few drops of urine were passed, with an osmolality of $378 \mathrm{mOsm} / \mathrm{kg}$. and a urinary urea concentration of
$360 \mathrm{mg} . / 100 \mathrm{ml}$. Obviously the renal function was deteriorating fast. His blood urea was $143 \mathrm{mg} . / 100 \mathrm{ml}$. and the plasma osmolality $286 \mathrm{mOsm} / \mathrm{kg}$. Since the urine/plasma osmolality ratio was not yet unity but 1.31 , it was thought that some residual function still remained. He was given $300 \mathrm{ml}$. of $5 \%$ mannitol intravenously at the rate of $10 \mathrm{ml} . /$ minute. There was a definite increase in diuresis, reaching $350 \mathrm{ml}$. in the next 12 hours. The next morning his blood urea rose to $264 \mathrm{mg}$. His urinary urea concentration increased to $700 \mathrm{mg}$. His urine osmolality improved to $508 \mathrm{mOsm} / \mathrm{kg}$. However, during all the morning marked oliguria was again observed. A second course of $300 \mathrm{ml}$. of $5 \%$ mannitol at the rate of $10 \mathrm{ml}$./ minute was given intravenously. Again there was an increase in the diuresis, which reached $400 \mathrm{ml}$. till the next morning, with a marked improvement in the urinary urea concentration which reached $3,020 \mathrm{mg}$. By then the blood urea had fallen to $173 \mathrm{mg}$. The next day a profuse diuresis started, with a urea concentration of $3,600 \mathrm{mg}$. The marked improvement in his renal function within 72 hours of the operation contrasted distinctly with the severe clinical condition of septicaemia and delirium. The blood urea decreased to normal within less than a week. On the sixth to eighth post-operative days there was an episode of dehydration with "contracted blood-volume," a high plasma osmolality (304 mOsm/ kg.), a high urine osmolality $(912 \mathrm{mOsm} / \mathrm{kg}$.), and a low urine sodium $(12 \mathrm{mEq} / \mathrm{l}$.). The patient made an uneventful recovery after this condition had been corrected by proper fluid and electrolyte replacement.

In summary, this case illustrates definite reversal of the rapid onset of the process of acute renal failure, which was most probably of the type of acute tubular necrosis. In retrospect, mannitol should have been given earlier and in larger doses.

\section{Oliguric Patients with Established Acute Renal Failure}

Two patients having acute oliguric renal failure, with very low urine-urea concentration and iso-osmotic urine and plasma, are considered. One, an 18-year-old, suffered from severe heat-stroke, which caused liver failure with deep jaundice (serum bilirubin $45 \mathrm{mg} . / 100 \mathrm{ml}$.) and oliguric renal failure. The other, a 73-year-old man, suffered from undetected peritonitis due to perforation of an intestinal diverticulum. In both cases mannitol had no effect whatsoever on diuresis or on

Details of 10 Cases with Low Urine Concentration and Four Cases with Normal Urine Concentration at Onset of Oliguria

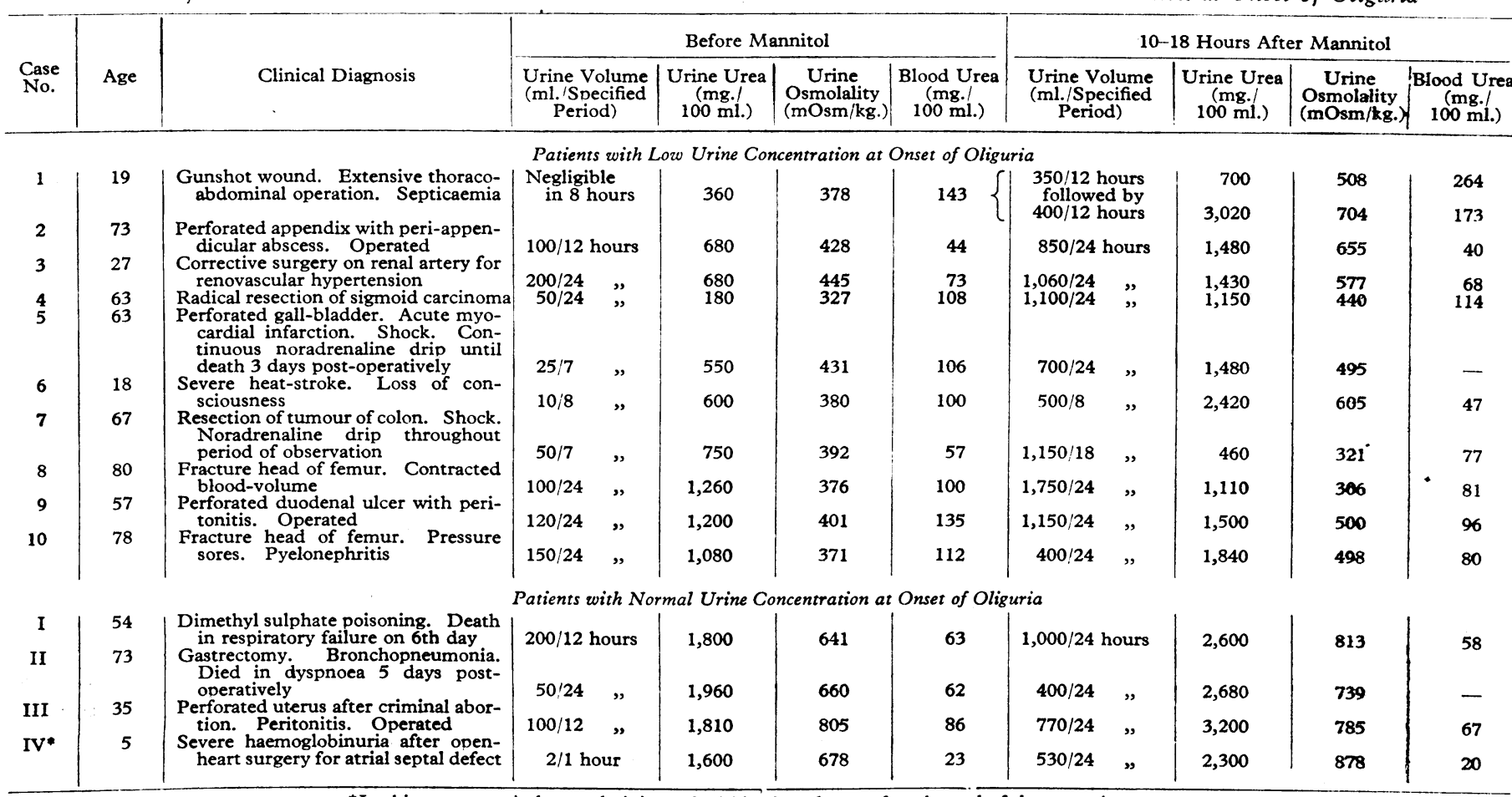

*In this case mannitol was administered within three hotrs after the end of the operation. 
urine concentration. Both patients died subsequently, and the diagnosis of acute tubular necrosis was confirmed at necropsy.

\section{Oliguric Patients with Good Urine Concentration}

Four patients who at the onset of oliguria had a rather high urine concentration are included in this group (see Table). Mannitol was given as a prophylactic in the hope of preventing the onset of genuine acute parenchymatous renal failure. In all of them adequate diuresis was obtained. Though the urine osmolality rose in three of them, it tended to remain in the vicinity of the pre-treatment level. It is interesting to note, however, that a significant rise in the urineurea concentration was obtained in all four.

In these patients the kidneys, as evidenced by good urinary concentration of urea and urine osmolality, were normal prior to the administration of mannitol. Since from the start no signs of genuine parenchymatous renal failure were present, the rise in the concentration of urea and the moderate rise in the urine osmolality after mannitol does not justify the assumption that acute renal failure was reversed. At best it can be argued that the possible onset of renal failure was prevented.

\section{Discussion}

The observation that mannitol not only promotes urine output in jeopardized kidneys but also restores concentrating power seems sufficient proof that the renal circulation and renal cell function are thereby improved. In normal hydropenic subjects urine osmolality decreases after the infusion of mannitol (Raisz and Scheer, 1959). Therefore mannitol per se cannot be the direct cause of the increase in the urine concentration in the cases presented.

Clinically, urine concentration in the oliguric patient is a good measure of renal function (or of the integrity of the kidney). Therefore a decrease in the power to concentrate is indicative of deterioration in renal function. This brings us to the concept of "incipient acute renal failure," where previously normal kidneys show a progressively diminishing ability to concentrate in spite of oliguria, a rise in blood urea, and/or a rapid catabolic rate. This is most probably a midway stage before the onset of genuine parenchymatous acute renal failure, and may be thought of as partial renal failure.

In all the 10 cases of "incipient acute renal failure" presented in the Table there was a definite increase in the concentrating power very soon after the administration of mannitol. This rapid improvement seems to be directly related to the mannitol therapy and not to spontaneous recovery, especially so since the patients' clinical condition did not change during the few hours between therapy and re-examination. In such cases reversal of incipient renal failure may be claimed.

In contradistinction to this group of incipient acute renal failure, the two cases with established acute tubular necrosis did not respond to mannitol at all.

With regard to the four patients with good urine concentration at the onset of oliguria the position is debatable. Since, by definition, no parenchymatous renal failure was present from the start, one cannot claim reversal of renal failure after mannitol, in spite of some rise in the urine osmolality and the urinary urea concentration. It can, however, be assumed, and be supported by the clinical course prior to the administration of mannitol, that the development of acute renal failure was probably prevented. It is, of course, difficult to argue that in this group diuresis could not have been achieved by other means, such as intravenous glucose. It is, however, highly probable that such an adequate diuresis could not have been obtained. This is supported by the observation of Bob et al. (1962) that the administration of $5 \%$ glucose in water failed to induce the significant diuresis produced by equivalent volumes of $10 \%$ mannitol in traumatized dogs. Probably only large-scale double-blind tests, such as the one planned by Nesbitt et al. (1962), could settle this argument.

It seems, therefore, that mannitol is most beneficial in the cases where acute progressive deterioration of renal function is occurring. Clinically, this finding seems to be synonymous with the reversal of the low urine concentration found in the presence of oliguria and the induction of adequate diuresis. In such cases reversal of incipient renal failure may be claimed to have been achieved by mannitol. As to the mechanism of reversal, the answer may be found in the experimental work of Murphy et al. (1963) on dogs. They have shown a significant increase in diuresis and in renal blood-flow as measured directly by cannulation of the renal vessels after intravenous mannitol, in spite of maintained hypotension.

\section{Summary}

The effect of mannitol on acutely failing kidneys was evaluated, the ability to concentrate the urine being used as a measure of renal function.

In all 10 patients who at the onset of oliguria had a low urine concentration prompt diuresis and a rise in urine osmolality and in urea concentration were obtained.

In two patients with established acute tubular necrosis no beneficial effects were observed.

In four patients who at the onset of oliguria had normal urine concentration, but seemed to be in the process of developing acute renal failure, diuresis was induced and the urine concentration maintained.

It is concluded that an incipient acute renal lesion may be reversed by the timely use of mannitol.

I am grateful to Dr. Y. Pauzner, head of the department of chest surgery ; to his senior assistants, Drs. Y. Kalter and Y. Lieberman ; and to Dr. S. Shibolet for early referral of the cases and for their co-operation. I am thankful to $\mathrm{Mr}$. Y. Benado for his technical laboratory help.

\section{REFERENCES}

Barry, K. G., Cohen, A., Knochel, J. P., Whelan, T. J., jun., Beisel, W. R., Vargas, C. A., and LeBlanc, P. C., jun. (1961a). Nero Engl. f. Med., 264, 967 . and LeBlanc, P. (1961b). Surgery, 50, 335

and Malloy, J. P. (1962). F. Amer. med. Ass., 179, 510.

Boba, A., Gainor, J., and Powers, S. R., jun. (1962). Surgery, 52, 188.

Eliahou, H. E. (1963). E. Afr. med. f., 40, 207.

Gullick, H. D., and Raisz, L. G. (1960). New Engl. ₹. Med., 262, 1309.

Hatcher, C. R., jun., Gagnon, J. A., and Clarke, R. W. (1958). Surg. Forum, 9, 106.

Hostnik, W. J., Powers, S. R., jun., Boba, A., and Stein, A. A. (1959). Ibid., 10, 872 .

Jacobson, M. H., Levy, S. E., Kaufman, R. M., Gallinek, W. E., and Donnelly, O. W. (1962). Arch. intern. Med., 110, 83. Lempert, N., Boba, A., and Powers, S. R., jun. (1961). Surg. Forum, 12,
90.

Leonhardt, K. O., and Landes, R. R. (1963). New Engl. f. Med., 269, 115.

Molloy, P. J. (1962). Lancet, 2, 696.

Murphy, G. P., Gagnon, J. A., and Teschan, P. E. (1963). F. Urol. (Baltimore), 90, 133.

Nesbit, R. M., Cerny, J. C., Heetderks, D. R., and Kendall, A. R. (1962) f. Urol. (Bal:imore), 88, 331.

Powers, S. R., jun., Boba, A., and Stein, A. (1957). Surgery, 42, 156.

Raisz, L. G., and Scheer, R. L. (1959). f. clin. Invest., 38, 1.

Selkurt, E. E. (1945). Amer. F. Physiol., 144, 395.

Seitzman, D. M., Mazze, R. I., Schwartz, F. D., and Barry, K. G. (1963). f. Urol. (Baltimore), 90, 139.

Shackman, R., Milne, M. D., and Struthers, N. W. (1960). Brit. med. F., 2, 1473. 